\title{
Periurbanización y diferenciación en el mercado de suelo urbano en Carabayllo*
}

\author{
Nekson Pimentel Sánchez \\ Uniiversidad Nacional Mayor de San Marcos \\ < neksonunmsm@hotmail.com >
}

RESUMEN:

Carabayllo, distrito de Lima Norte, en las últimas décadas, ha experimentado una pérdida sustancial de tierras agrícolas periurbanas debido al desarrollo de programas inmobiliarios, proceso con repercusiones en el estilo de vida, las relaciones sociales, así como en las formas y mecanismos de posesión espacial.

Este artículo, de manera sinóptica y específica, y en base a datos recopilados en trabajo de campo, tiene el propósito de analizar los procesos de periurbanización y diferenciación que produce el mercado de suelo urbano en Punchauca, uno de los centros poblados de Carabayllo.

Palabras clave: Periurbanización; mercado de suelo; urbe; diferenciación; Carabayllo.

\section{Peri-urbanization and differentiation in the urban soil market in Carabayllo}

\begin{abstract}
Carabayllo, district of North Lima, in the last decades, has experienced a substantial loss of periurban agricultural land due to the development of real estate programs, process with repercussions in the lifestyle, social relations, as well as in the forms and mechanisms of possession space.

This article, in a synoptic and specific way, and based on data collected in field work, has the purpose of analyzing the processes of periurbanization and differentiation produced by the urban land market in Punchauca, one of the populated centers of

Carabayllo.
\end{abstract}

KeYwords: Periurbanization; soil market; city; differentiation; Carabayllo.

\footnotetext{
Este artículo es una versión revisada y aumentada de algunas partes de la tesis «Subalternos autónomos: transformaciones periurbanas y tráfico de tierras en el contexto de una sociedad de mercado: Carabayllo, Lima». Véase Pimentel (2017a). Lima: UNMSM.
} 


\section{Introducción}

$\square^{a}$ n un balance reciente, Julio Calderón (2006), a partir de la recuperación de ideas de Stren, argumenta que la investigación en América Latina en torno al tema del mercado de suelo urbano ha sido poco abordada empíricamente y se encuentra en una situación emergente, y que, por el contrario, los procesos de urbanización y la producción de la vivienda han merecido mayor atención. Dentro de los componentes del mercado de suelo, la investigación de Calderón está referida a los mercados informales e ilegales de la tierra urbana. Considera que «en América Latina el mercado informal e ilegal de tierras urbanas se ha constituido en el principal mecanismo de acceso al espacio para amplios sectores de la población, superando como medio a las invasiones que, hacia los sesenta, se pensaba que iban a ser predominantes» (pp. 18-19).

Este texto, con el fin de aportar en el abordaje de estos temas, tiene el propósito de analizar, desde la etnografía, las actitudes, motivaciones, ideas y vínculos de los diferentes agentes o sujetos dentro de la dinámica del mercado de suelo urbano. Se considera que las transformaciones espaciales son expresión de los cambios de la vida de los sujetos sociales y viceversa, por lo que se presta atención a las tensiones y conexiones, alianzas y contraposiciones entre los sujetos.

En síntesis, abordará las implicaciones de los procesos de periurbanización, el desarrollo del sistema inmobiliario, así como la diferenciación de los sujetos implicados en el mercado de suelo urbano en Punchauca.

\section{Periubanización: relaciones entre lo rural y lo urbano}

Dentro de la literatura de las ciencias sociales se ha recurrido al uso de lo urbano y lo rural bien como categorías dicotómicas o para hacer referencia a dos territorios relacionales. El Estado, por su parte, aún percibe a dos áreas con diferencias bien marcadas, al primero como desarrollado y al área rural prefigurado por la ausencia de desarrollo infraestructural y vinculado sobre todo a la producción agrícola, incluso, es definido por exclusión a las características de lo urbano (véase tabal 1). La ciudad, a su vez, aún es percibida como aquella área más administrativa, donde es posible acceder a derechos y servicios, educación, salud, etc. Como señala Remy, «la «urbanidad» o «ruralidad» del país o de una zona, siguen siendo evidencias de su nivel de desarrollo» (Remy 2009: 1). Esta concepción dicotómica es producto de una sociedad jerarquizada en que la tensión y la polaridad se desarrollan en la vida cotidiana y en las dimensiones institucionales. Es parte de una sociedad donde se imagina a los otros pero no necesariamente interactuando con ellos.

Es abundante la literatura en ciencias sociales, sobre todo en la sociología, sobre la relación existente entre campo y ciudad, ciudad y rural, incluso los cambios de uno al otro (Lefebvre 2013[1974], 1978 y 1974; Matos 1986; Monge 2012; Williams 2001, entre otros). Sin embargo, no se ha prestado atención a los espacios en estado de transición, aquellos que se encuentran entre lo rural y lo urbano y que contienen un entramado de alianzas y tensiones. Los cambios en las ciudades en términos de su expansión y formas de influencia sobre áreas contiguas abren nuevas alternativas para entender las relaciones sociales, los movimientos sociales, las formas de uso de la tierra y la naturaleza de la formación de nuevos asentamientos urbanos.

La periurbanización es un estado transicional del campo a la ciudad, de lo rural a lo urbano, y comporta aspectos de ambas áreas de manera difusa. Pero, sobre todo, lo periurbano refiere a ámbitos que no son propiamente rurales ni propiamente urbanos. Sin embargo, las características urbanas son cada vez más determinantes e irreversibles, definen las prácticas, la organización del trabajo, las relaciones sociales y los estilos de vida. El proceso de periurbanización disuelve la representación dicotómica entre campo y ciudad.

Los espacios periurbanos son espacios de alta interacción y movilidad entre sujetos de diferentes sujetos, sean estos de regiones, provincia o de ámbitos rurales y urbanos. Mediante la provisión de productos alimenticios de primera necesidad y de pan llevar que salen de los espacios periurbanos sirven de sustentos para la ciudad. Del mismo modo, en el ámbito de relación laboral, muchos sujetos que habitan la ciudad se trasladan a estos espacios sea en calidad de jornaleros o como propietarios de inmobiliarias y parcelas en proceso de producción agropecuaria.

Los territorios urbano-rurales sirven como espacios de extensión urbanística y son afectadas de manera acelerada por las políticas urbanas, económicas $\mathrm{y}$ sociales. Sus habitantes interactúan de manera constante con la ciudad, por lo que sus imaginarios no 
son ajenos, ni distintos a los hábitos y prácticas propias de la ciudad. Las ocupaciones de áreas periurbanas son efectuadas mediante toma de tierras y la estructura urbanística se desarrolla de acuerdo a la dirección de las vías de comunicación que permiten la conexión local e interregional. La formación de barrios, calles y manzanas son definidas en alguna medida por las redes viales cercanas. También los cambios conviven con elementos peculiares. Los espacios en transición han sido considerados desde diversas miradas, pero estas coinciden en dos aspectos de la periurbanización: un proceso de urbanización disperso y el carácter polifuncional del espacio.

Héctor Ávila Sánchez señala que «hasta finales de años setenta, cuando se hacía referencia a la periferia urbana, se consideraba un espacio subordinado al ámbito central de la ciudad, muy lejano, pero fuertemente implicado con los componentes rurales adyacentes. Forma parte de lo que se ha llamado "modelo territorial flexible», que al fragmentar territorialmente los sistemas productivos afecta a los sistemas urbanos y subsistemas que lo integran" (Ávila 2009: 95).

Pero en la actualidad los espacios periurbanos se pueden ver fortalecidos debido a la expansión urbana de Lima Metropolitana, cuyos límites no son definidos y muestran un escenario confuso, convirtiéndose en un nuevo modelode desarrollo urbano. Laperiurbanización limeña se caracteriza fundamentalmente por una constante movilidad socioespacial, la descentralización de las actividades productivas, el tráfico de terrenos, las prácticas clientelares en la posesión del espacio y la pérdida de acceso al trabajo en el sector rural, sobre todo para los jornaleros agrícolas.

En tanto, la descentralización de actividades productivas está asociada a la existencia de nuevas lógicas económicas. Las funciones de la actividad agropecuaria son interferidas y desplazadas por actividades inmobiliarias, el ocio, el tráfico de terrenos y el establecimiento de pequeñas actividades industriales. El nuevo escenario, en un contexto de expansión urbana y de una sociedad de mercado, muestra opciones limitadas a los parceleros y jornaleros: una de las posibilidades es la inserción a labores propias de la urbe, como comerciantes, albañiles, ambulantes, entre otros. Esto evidencia que la periurbanización es un proceso de transformación espacial, por un lado, y de la formación de nuevos estilos de vida, por el otro.
Implica un conjunto de cambios sociales, políticos, económicos, culturales, e incluso socio-ambientales.

Lo periurbano refiere a un escenario difuso en que se evidencia la fragmentación territorial y social y, al mismo tiempo, se visibiliza la ausencia de un desarrollo urbano planificado ${ }^{1} \mathrm{y}$, por tanto, la inexistencia de decisiones con el fin de constituir redes de ciudades. Lima, en términos de expansión urbanísticas, es una ciudad que absorbe todo espacio contiguo, no permite la existencia de un medio rural entre ciudad y ciudad. Los distintos centros poblados de sus tres valles (Rímac, Chillón y Lurín), que hasta los setenta fueron centro de administración de las haciendas, ${ }^{2}$ son absorbidos de manera paulatina por la ciudad de Lima, cuyas dinámicas cambian las funciones territoriales de las áreas que sirvieron para la producción primaria.

En el cambio de funciones territoriales, de agrícolas a asentamientos urbanos, se presentan resistencias de los sujetos respecto a poner en oferta o no sus tierras. La fragmentación social latente y evidente está en que la lotización de tierras agrícolas para vivienda y la toma de tierras baldías reproducen tensiones entre los sujetos que buscan intereses individuales y familiares a partir de una organización colectiva. Francisco Entrena observa que estos procesos permiten una constante indefinición de las actividades socioeconómicas, culturales y físicas entre el ámbito rural y urbano (Entrena 2005).

Entrena presenta evidencias empíricas sobre transformaciones de estas áreas en Europa: ciudades principales de Francia, Alemania, España e Inglaterra, experimentan cambios cuyas contradicciones por el suelo han sido protagonizadas, fundamentalmente, entre las actividades agrícolas e industriales. En caso de España, los ejidos han venido siendo reemplazados por la formación y expansión de grandes ciudades. En contraste, en las áreas de nuestra investigación no necesariamente la funcionalidad del suelo radica en el reemplazo de las actividades agrícolas por las actividades industriales. En áreas periurbanas de Carabayllo hay un aumento de reemplazo de las áreas agrícolas por las actividades inmobiliarias, comerciales y la formación de nuevos asentamientos urbanos. El avance de la urbe significa también una tendencia creciente del valor de cambio de los terrenos.

1 Véase Pimentel (2017b: 17). En la entrevista, Gustavo Riofrío refiere que el desorden del crecimiento urbano en Lima se debe a la falta de una visión urbanística y la pérdida de vista sobre las características de las ciudades como punto de encuentro y el punto de la creatividad.

2 Véase Malpica (1975); Quispe y Tacunán (2011) y Távara (2007; 2014). 
TABLA 1 DEFINICIÓN DE POBLACIÓN URBANA Y RURAL EN LOS CENSOS NACIONALES (1940-2007)

\begin{tabular}{|c|c|c|}
\hline Censo & Población urbana & Población rural \\
\hline 1940 & $\begin{array}{l}\text { La que habita en las capitales de circunscripción territorial (departamento, } \\
\text { provincia y distrito); asimismo, la que vive en centros poblados cuyo número } \\
\text { de habitantes excede del promedio aritmético del de dichas capitales, } \\
\text { siempre que no tengan características típicamente rurales (hacienda, fundo, } \\
\text { comunidad, y otros). }\end{array}$ & Su definición por exclusión. \\
\hline 1961 & $\begin{array}{l}\text { La que habita en los centros poblados designados como capitales de distrito, } \\
\text { sea cual fuere el número de habitantes. } \\
\text { No importa que se trate de ciudades, villas o pueblos. Por excepción, aunque } \\
\text { no es capital de distrito, se considera como área urbana el territorio ocupado } \\
\text { por un centro poblado cuyas características lo determinen como tal, por } \\
\text { tener calles, plazas, servicios de agua, desagüe, alumbrado y un número de } \\
\text { habitantes igual o mayor que el de la capital del mismo distrito. }\end{array}$ & $\begin{array}{l}\text { La que habita en la parte del territorio de un } \\
\text { distrito que se extiende desde los linderos del } \\
\text { pueblo capital hasta los linderos del mismo distrito. } \\
\text { Dentro de esa área se incluyen necesariamente los } \\
\text { caseríos, fundos, haciendas, anexos, pagos y otros } \\
\text { que no tengan características de centro poblado } \\
\text { urbano. }\end{array}$ \\
\hline $\begin{array}{l}1972, \\
1981 \text { y } \\
1993\end{array}$ & $\begin{array}{l}\text { Aquella que vive en aglomeraciones cuyas viviendas, en número mínimo de } \\
100 \text {, se hallen ocupadas contiguamente. Por excepción, se considera como } \\
\text { población urbana a aquella que habita en todas las capitales de distrito. Las } \\
\text { aglomeraciones pueden contener uno o más centros poblados con viviendas } \\
\text { contiguas. }\end{array}$ & $\begin{array}{l}\text { Aquella que habita en la parte del territorio del } \\
\text { distrito que se extiende desde los linderos de los } \\
\text { centros poblados en área urbana, hasta los límites } \\
\text { del mismo distrito. }\end{array}$ \\
\hline 2007 & $\begin{array}{l}\text { En el Censo 2007, el centro poblado urbano es aquel tiene como mínimo } 100 \\
\text { viviendas agrupadas contiguamente. } \\
\text { En la ENAHO, Se considera como área urbana los centros poblados con } 400 \text { a } \\
\text { más viviendas ( } 2000 \text { y más habitantes). }\end{array}$ & $\begin{array}{l}\text { El Censo 2007, considera como área rural son los } \\
\text { Centros Poblados restantes. } \\
\text { EI ENAHO, considera el área rural a los demás } \\
\text { centros poblados. }\end{array}$ \\
\hline
\end{tabular}

Fuente: Taller de teoría y definición urbano-rural, INEI y UNFPA 2010.

Elaboración: El autor.

Los espacios periurbanos no son ajenos de los contextos de tensión o conflicto debido al surgimiento de nuevos asentamientos y las relaciones que implica. Son espacios en constantes crisis (Entrena 2005: 69), en que las áreas transformadas no volverán a recuperar sus características precedentes, sea en términos espaciales, económicas y sociales. Son espacios de una alta transformación, desde los formas de pensar hasta las maneras de actuar, vivir y relacionarse.

\section{Diferenciación en el mercado de suelo urbano en Punchauca}

El proceso de parcelación de las cooperativas agrícolas en los ochenta ${ }^{3}$, la instalación de la empresa Agua Azul y la expansión urbana de Lima Metropolitana son procesos interconectados que han condicionado la

3 Mediante el Decreto Legislativo 2, del 17 de noviembre de 1980, el segundo gobierno de Fernando Belaunde Terry permitió la parcelación de las cooperativas formadas durante la Reforma Agraria desarrollada por el gobierno de Juan Velasco Alvarado. «A partir de ese momento, el proceso de parcelación tomó un ritmo imparable y como resultado, en junio de 1990, de un universo de 609 cooperativas agrarias, de las cuales 596 eran de producción, se habían parcelado un total de 472 cooperativas (339 con proceso regular aprobado, 47 parceladas en proceso de regularización y 86, parceladas de hecho)» (Thays 1996: 35). configuración de la dinámica del sistema inmobiliario que hoy genera cambios sustanciales en la estructura de la tenencia de tierra, el uso del suelo y la producción de hábitat en el Centro Poblado de Punchauca.

El mercado de suelo ha producido un escenario de tensión intergeneracional entre los miembros de las familias, fundamentalmente entre parceleros beneficiarios de la Reforma Agraria y sus hijos. La Reforma Agraria significó un giro de la propiedad individual a la propiedad colectiva de la tierra que era la cooperativa, mientras que la parcelación significó el retorno de la propiedad colectiva a la individual, pero bajo situaciones y condiciones diferentes: $\sin$ la presencia del poder comercial del terrateniente o hacendado.

El desarrollo del sistema inmobiliario, además, ha significado no solo una acelerada transformación de áreas agrícolas periurbanas sino, y sobre todo, el surgimiento de nuevas relaciones sociales en el proceso de expansión de la Metrópoli limeña ${ }^{4}$, marcadas por relaciones de desigualdad y del establecimiento de

\footnotetext{
4 Pedro Jacinto Pazo (2014) define a Lima como Metrópoli multicéntrica, en tanto Roberto Arroyo $(2014 ; 2015)$ plantea una metrópoli policéntrica haciendo referencia al suceso de Lima de como ciudad costa-andina. Véase también sobre este proceso a Calderón (2005) y Vega Centeno (2004).
} 
prácticas clientelares. El proceso de diferenciación y disputa es lo que marca el mercado de suelo urbano. Se identifican diferentes agentes que se diferencian por el uso del capital, sus deseos y decisiones, el rol que cumplen, los mecanismos y estrategias que tejen: 1) Propietarios inversionistas, 2) Hijos de parceleros que forman empresas inmobiliaria (autónomos), 3) parceleros patrimonialistas y 4) parceleros con alianzas estratégicas, 5) intermediarios inmobiliarios.

\subsection{Propietarios inversionistas}

No tienen ningún vínculo parental con los parceleros de Punchauca, tampoco viven en este centro poblado. Sus vínculos no son sino por el intercambio de propiedades inmobiliarios, compran terrenos agrícolas a los parceleros con fines de lotizar y desarrollar programas inmobiliarios.

Son cerca de doce inmobiliarias en total las que existen de acuerdo al registro que hemos elaborado hasta el 15 de febrero de 2015, pero de las cuales más de la mitad son empresas externas que se han instalado en la última década. Los propietarios inversionistas han realizado programas en otras partes de la provincia y región de Lima. Por ejemplo, la empresa inmobiliaria Inversiones Mendoza se formó en 1989. Desde entonces ha llevado a cabo proyectos de lotización, compra y venta de terrenos, en gran parte de Lima Metropolitana y Lima provincias: Lurín, Rímac, Carretera Central y valles del Norte Chico. Una de las dueñas de esta inmobiliaria señala que los precios de los terrenos en el valle del Chillón son de bajo precio, razón por la cual prefieren desarrollar programas inmobiliarios en este valle. Esto evidencia que su racionalidad es económica y buscan la máxima ganancia. Se encuentran dos años en Punchauca.

El mecanismo de las inmobiliarias para con los parceleros es la persuasión. Se ha evidenciado que varios parceleros mantienen resistencia a la venta de sus terrenos. Las inmobiliarias externas convencen a los parceleros recurriendo a las supuestas dificultades que tendrían si venden sus tierras de manera autónoma. Los mecanismos de persuasión esconden ciertas desigualdades y relaciones de poder. Las inmobiliarias, sin duda, se encuentran en una ventaja amplia para poder tramitar la habilitación urbana, mientras que los parceleros, en su mayoría, presentan ciertas dificultades para habilitar y lotizar sus tierras, porque todo ello implica una inversión: contrato de especialistas para el estudio topográfico y la medida de los lotes, documentación para habilitación urbanas, entre otros. A esto se suma la edad de muchos parceleros, que sobrepasa los setenta años. Sus hijos no muestran casi ningún interés por mantener y cultivar las tierras agrícolas, debido a que se encuentran desvinculados de la producción agropecuaria, no existe ninguna estructura afectiva por el campo ni por la producción agrícola.

Las inmobiliarias desarrollan programas dependiendo de las hectáreas que logran comprar. Cada programa tiene una denominación (Villa Esperanza, Los Robles, Surco, etc.) y comprende un determinado número de lotes, circunscritos en cuatro o más manzanas. Un programa puede tener una duración de tres a cuatro meses, y depende propiamente de la demanda. Muchas tierras pueden estar en arriendo pero en paralelo se pueden establecer las negociaciones para la compra de la parcela por las inmobiliarias.

La negociación por el espacio entre el parcelero y la inmobiliaria es previa al desarrollo del programa mientras el pago por el mismo es durante el desarrollo del programa. Las evidencias del trabajo de campo muestran que muchos programas se desarrollan al lado de hectáreas de cultivo de productos de panllevar pero que ya se compradas para el desarrollo de un nuevo programa. Existe un cambio acelerado y, como todo proceso histórico, sin opciones de retroceso.

Los terrenos de los programas adyacentes a las avenidas tienen mayor demanda, por lo que tienen mayor valor de cambio. Depende de las inmobiliarias que el valor de cambio de los terrenos tenga una tendencia creciente. Los precios de los terrenos, tomando referencia la medida, varían entre 320 a 400 dólares el metro cuadrado (Véase tabla 2). Uno de nuestros interlocutores señaló el valor de cambio de los terrenos crece cada quince o treinta días. Estas empresas desarrollan programas inmobiliarios con servicios provisionales de agua y luz.

El mayor alcance en cuanto a áreas de ejecución es otra de los aspectos centrales de las inmobiliarias externas. Por el alcance que tienen, desarrollan generalmente más de tres programas al mismo tiempo, mientras que las empresas de los hijos de los parceleros ejecutan un solo programa.

Además, las inmobiliarias cuentan con promotoras de venta, contratadas por ciertas modalidades que será explicado más adelante. La propiedad inmobiliaria, de manera directa, tiene relación directa con la 
desaparición paulatina de áreas agrícolas del valle del Chillón.

Las oficinas de estas empresas suelen no estar en el Centro Poblado de Santiago de Punchauca, se encuentran en otros distritos de Lima Metropolitana. Estos empresarios fueron denominados por el urbanista Carlos Morales como propietarios inversionistas, sujetos que obtienen terrenos con fines propiamente mercantiles:

[Es quien] adquirió un terreno para obtener ganancia cuando menos a la tasa de media que un capital similar rendiría en el mercado de capitales, desde luego que si puede obtener una ganancia superior invirtiendo en un terreno preferirá esta inversión a la de otro sector de la economía (Morales 2005: 1).

Los terrenos que compran no son sino para la venta a los diversos usuarios que buscan un lote para vivienda o para otros fines. Actúan de acuerdo a una racionalidad económica. Su existencia y permanencia se fundamenta en la eficacia de la compra y venta de lotes. Tienen como intermediarios inmobiliarios principalmente a mujeres.

\subsection{Propietarios autónomos}

Son hijos de parceleros que han constituido sus propias empresas inmobiliarias. Su naturaleza se fundamenta en la existencia de vínculos parentales más cercanos y no depende necesariamente de las empresas inmobiliarias externas para su funcionamiento y el desarrollo de programas inmobiliarios. Pueden habitar la casa de sus padres o en propiedades que tienen en otras partes de la ciudad.

En contraste con los propietarios inversionistas, tienen alcances limitados en el desarrollo de programas inmobiliarios, generalmente lotizan y promocionan parcelas que fueron de sus padres. Como es sabido, durante el proceso de parcelación, cada miembro de la cooperativa recibió entre tres a cuatro hectáreas. El capital con que cuentan no les permite desarrollar programas en territorios externos a Punchauca. Existe relación parental y estructura afectiva entre los miembros implicados en la mediación de los programas: los intermediarios inmobiliarios son fundamentalmente familiares o amigos, es decir, del círculo interno del propietario.
Detrás de la formación de estas empresas autónomas se esconden situaciones de tensión intergeneracionales de padres e hijos. Los padres o parceleros originales no pretenden vender sus hectáreas de tierras, en su imaginario se encuentran insertos el apego de mantener el campo, la producción agrícola y el ambiente al que han estado ligadas sus actividades de existencia. No obstante, al perder ciertas facultades por tener mayoría de edad (como no poder firmar documentos o perder capacidad de lectura de documentos, o, también, en caso de fallecimiento), son los hijos quienes toman decisiones sobre la situación de la propiedad. Existen casos en que no todos los hijos de los parceleros originales están implicados en la formación de las empresas inmobiliarias autónomas, debido a la prioridad de las ocupaciones o trabajos distintos que tienen. En este caso, las mismas viviendas de los parceleros, o de familiares, pueden servir como centros de atención, casi siempre a cargo de promotoras o intermediarios inmobiliarias. Llamó nuestra atención algunas promotoras de estas empresas inmobiliarias autónomas que presentaron resistencia a brindar información respecto al número de partida y el nombre de la empresa. Aquí, una reconstrucción de una conversación con una de las promotoras, que registramos en uno de los trabajos de campo en febrero de 2015:

-¿Cuál es el nombre de la inmobiliaria?

-No le puedo decir por ahora.

- ¿Cómo los interesados se aseguran de qué empresa están comprando sus lotes?

-Cuando los clientes finalmente separen sus terrenos y \{estén dispuestos a comprar, recién allí le damos el nombre de la empresa, antes no.

-iPero si necesito saber sobre la situación de la inmobiliaria, no puedo pagar por un lote si no sé de qué empresa se trata?

-Joven, estamos tratando de manera directa, somos propietarios directos, parceleros. Mi tío es el dueño, yo trabajo para él. Es barato y seguro el lote que vendemos.

- ¿La empresa lleva el nombre de su tío?

-No puedo decirle.

-Bueno, de todos modos, muchas gracias.

Como es posible apreciar, la promotora de venta se resiste a brindar el nombre de la empresa inmobiliaria. Esto ocurre debido a que muchas de estas empresas familiares se encuentran, según la clasificación de 
Calderón (2005) y de De Soto (1986), dentro de la informalidad, pero puede suceder también que una supuesta empresa formal estédesarrollando un programa sin haber cumplido con todos los procedimientos necesarios para la lotización y promoción del terreno. Es importante, por eso, analizar el sentido del silencio en estos espacios donde la informalidad y la alegalidad tienen conexión y complementariedad. Más preciso aún: las prácticas de los sujetos están marcadas más por la alegalidad que por la informalidad, sea a través de la instrumentación de elementos, la búsqueda de vacíos legales o a través de la red clientelar con instituciones del Estado para facilitar procedimientos que permitan la aprobación de la lotización sin estudios de suelo. Una empresa por más formal que se muestre no está lejos de actos ilícitos. Así, el delito se presenta legal. La alegalidad, en tanto, constituye un conjunto de estrategias de relación social en búsqueda de privilegios y enriquecimiento. En estos espacios en tensión, el silencio debe ser tomado en cuenta como un elemento de análisis debido a que puede dar mayores luces sobre la naturaleza y dinámica de muchas empresas promotoras del suelo urbano.

\subsection{Propietarios patrimonialistas}

Son propietarios que fueron beneficiados por la Reforma Agraria, llevada a cabo durante el gobierno de Juan Velasco Alvarado (1969-1975), y hoy mantienen una resistencia ante ofertas de empresas inmobiliarias para la venta de sus parcelas para el desarrollo de programas inmobiliarios. La mayoría de ellos $^{5}$ son personas de tercera edad, ya no trabajan sus tierras de manera directa, sobre todo por las dificultades que tienen, porque esto equivale a una inversión considerable de capital para los medios de producción: alza de químicos, escasez de fuerza de trabajo, falta de semillas y el pago por agua de riego al Ministerio de Agricultura y Riego. Por esta razón, muchos de ellos han optado por el sistema de arriendo.

Estos parceleros mantienen sus terrenos mediante el sistema del arriendo. Alquilan sus tierras por seis o doce meses, con una renta que puede variar entre tres a cuatro mil por semestre. Pero algunas resistencias son temporales porque luego establecen alianzas con algunas inmobiliarias externas. En los noventa

5 El detalle del proceso de resistencia ha sido desarrollado en otro trabajo (Pimentel 2017c). pasó algo semejante con la instalación de la empresa italiana Agua Azul; esta empresa empezó a comprar aceleradamente terrenos de los parceleros para construir un cerco del total de su territorio, entonces los parceleros construyeron la idea de que la empresa, al necesitar más terrenos, iba a pagarles un monto mayor, razón por la cual optaron por una resistencia frente a la actitud persuasiva de la empresa; pero llegó el momento en que la empresa cesó en la compra de tierras y la proyección de los parceleros de resistencia estratégica quedó trunca. Esto evidencia que el estilo de vida, es decir, las prácticas de los individuos ya empezaba a tener matices de la oferta y la demanda. Ahora, con la empresa inmobiliaria sería un segundo momento de este tipo de resistencias.

Estas características de los comportamientos de los sujetos es lo que Carlos Morales (2005) ha denominado como propietarios patrimonialistas. Son sujetos sin ninguna presión para la venta inmediata de sus terrenos. Existen casos en que estas resistencias disimulan ciertos intereses materiales y de acumulación de capital, es decir, prefieren no vender sus hectáreas de tierras porque han podido constatar que los precios de las propiedades inmobiliarias tiene un sentido creciente con el tiempo.

Sin embargo, dentro de los propietarios patrimonialistas encontramos también a aquellos que se resisten a la venta de sus parcelas por asuntos éticos y políticos, es decir, por el gran sentido simbólico que comporta y ser un elemento de memoria de las luchas para el acceso a la tierra de los campesinos durante los procesos de Reforma Agraria.

\subsection{Propietarios mixtos}

Son parceleros que mantienen alianzas con empresas inmobiliarias; son sujetos sociales dispuestos a vender sus tierras para la habilitación urbana y el proceso de urbanización pero mantienen limitaciones económicas para concretizar de manera autónoma y, por tanto, para lotizar y vender sus tierras, necesitan de otros agentes que no son sino las empresas que desarrollan programas inmobiliarios. Esta relación, indudablemente, es de carácter asimétrico, porque hay un predominio de las reglas de juego de las empresas inmobiliarias sobre aquellas planteadas por los parceleros. Los puntos que marcan esta alianza son fundamentalmente dos: a) el beneficio de la inmobiliaria de una parte de las ganancias obtenidas por la venta de cada terreno por 
TABLA 2: RELACIÓN DE EMPRESAS QUE DESARROLLAN PROGRAMAS INMOBILIARIOS EN PUNCHAUCA (2015)

\begin{tabular}{|c|c|c|}
\hline Empresa Inmobiliaria & Programa & Precio por lote \\
\hline \multirow[t]{2}{*}{ RREAL } & \multirow[t]{2}{*}{ Zaire } & $119 \mathrm{~m} 2=\$ 34,510$ \\
\hline & & $97.50 \mathrm{~m} 2=\$ 28.275$ \\
\hline LLAIRES & Costa Azul & $153.99 \mathrm{~m} 2=\$ 36.957$ \\
\hline \multirow[t]{10}{*}{ Inmobiliaria López } & Las Almendras & $105 \mathrm{~m} 2=\$ 35.700$ \\
\hline & Villa Valencia & $132.63 \mathrm{~m} 2=\$ 45.094$ \\
\hline & Villa Esperanza & $92.37 \mathrm{~m} 2=\$ 31,405$ \\
\hline & Villa Rivera & $109,63 \mathrm{~m} 2=\$ 36,177$ \\
\hline & \multirow[t]{3}{*}{ Los Pinos } & $180 \mathrm{~m} 2=\$ 63,000$ \\
\hline & & $108.57 \mathrm{~m} 2=\$ 37,999$ \\
\hline & & $90 \mathrm{~m} 2=\$ 31,500$ \\
\hline & \multirow[t]{3}{*}{$\begin{array}{l}\text { Venta de terreno de parcelero (en Primavera } \\
\text { y Torre Blanca) }\end{array}$} & $\begin{array}{c}126.88 \mathrm{~m} 2=\$ 37,914 \text { (1500 soles por derecho de lotización, no } \\
\text { hay cuota inicial: programa Primavera, lote de parcelero) }\end{array}$ \\
\hline & & $250 \mathrm{~m} 2=\$ 45,000$ \\
\hline & & Aquí el precio es al contado. No piden inicial \\
\hline & Los Lirios & $120 \mathrm{~m} 2=\$ 36,000$ \\
\hline \multirow[t]{3}{*}{ JOE S.A. } & Surco & $136.56 \mathrm{~m} 2=\$ 43,692$ \\
\hline & & $123,01 \mathrm{~m} 20=\$ 31,490.56$ \\
\hline & Costa Azul & $90 \mathrm{~m} 2=\$ 19,800$ \\
\hline ILLA RUMI S.A.C & \multicolumn{2}{|c|}{ Esta inmobiliaria supervisa la parte legal de las demás inmobiliarias, y de modo específico a JOE S.A.C } \\
\hline \multirow[t]{5}{*}{ G.M.R Caballero } & Almendras & $105,02 \mathrm{~m} 2=\$ 35,700$ \\
\hline & Villa Rivera & $121.80 \mathrm{~m} 2=\$ 41,412$ \\
\hline & Ciudad Jardín & $123,50 \mathrm{~m} 2=\$ 39,520$ \\
\hline & Los Robles & $120 \mathrm{~m} 2=\$ 24,000$ \\
\hline & Villa Esperanza & $92,37 \mathrm{~m} 2=\$ 25,863.6$ \\
\hline Inversiones Mendoza SAC & $\begin{array}{l}\qquad \text { Los Robles } \\
2 \text { años en Punchauca, pero como empresa } \\
\text { existe desde } 1989 .\end{array}$ & $90 \mathrm{~m} 2=\$ 16,000$ \\
\hline Inversiones Zaire S.A. & Los Olivos & $121.87 \mathrm{~m} 2=\$ 38,998.98$ \\
\hline $\begin{array}{l}\text { Consorcio Inmobiliario G y D } \\
\text { (Emilio y Desideria) }\end{array}$ & $\begin{array}{l}\text { La Florida II } \\
\text { (Anteriormente ejecutaron otro programa en } \\
\text { Huacoy, «Florida I»). } \\
\text { Inmobiliaria formada por hijos de parceleros }\end{array}$ & $\begin{array}{c}120.05 \text { m2= } \$ 320 \text { el m2 (10 años) } \\
105 \text { m2= } \$ 330 \text { el m2 } \\
\text { (10 años. }\end{array}$ \\
\hline $\begin{array}{l}\text { Consorcio Inmobiliario Santa } \\
\text { Catalina S.A.C. }\end{array}$ & $\begin{array}{l}\text { Las Palmeras-III Etapa } \\
\text { Empresa de dos de los tres hijos de los } \\
\text { parceleros (padres). Falleció la madre. }\end{array}$ & $\begin{array}{c}90 \mathrm{M} 2=\$ 28,000 \\
(\$ 320 \text { el m2; } 90 \text { letras })\end{array}$ \\
\hline ICOMAR S.A.C. & $\begin{array}{l}\text { Santa Teresa } \\
\text { Vende la tierra de los parceleros mediante } \\
\text { una alianza con ellos. }\end{array}$ & $\begin{array}{c}105.43 \mathrm{~m} 2=\$ 33,737 \\
(\$ 320 \text { el m2) } \\
95.06 \mathrm{~m} 2=\$ 30,419 \\
(\$ 320 \text { el m2) }\end{array}$ \\
\hline Empresa de parcelero $X^{*}$ & $\begin{array}{l}\text { Villa Victoria de Carabayllo } \\
\text { Empresa de parceleros, cuyos intermediarios } \\
\text { inmobiliarios son familiares }\end{array}$ & $\begin{aligned} 126 \mathrm{~m} 2 & =\$ 39,060 \\
140 \mathrm{~m} 2 & =\$ 43,400 \\
108 & =\$ 33,480\end{aligned}$ \\
\hline
\end{tabular}

Fuente: Cuaderno de campo, 2015.

Elaboración: El autor.

* Se describe como «Empresa de Parcelero X» porque la promotora, quien menciona ser sobrina del dueño, decidió no brindar información sobre el nombre de la empresa. Aseguró que eso es posible solo cuando el cliente decide finalmente comprar el lote. 
un lado; y b) la venta por parte del parcelero a la inmobiliaria de sus parcelas por debajo del precio del mercado y en un plazo extenso.

Las empresas inmobiliarias tienen acceso a mayores facilidades para desarrollar programas inmobiliarios. Los parceleros con quienes establecen alianzas estas inmobiliarias pueden permitirles acceder a terrenos cuyos precios sean más bajos. Ninguna de las inmobiliarias externas compra terrenos de los parceleros al contado, sino lo hacen de acuerdo a la eficacia del programa, es decir, de acuerdo a los lotes que se van vendiendo de cada programa, por lo que aquí existe una suerte de hacer negocios con terrenos aún no pagados. Terminan de pagar el precio de la hectárea cuando han logrado vender todos los lotes del programa.

Aquí queremos recuperar un breve diálogo, registrado en un trabajo de campo en enero de 2015, con uno de nuestros informantes que trabaja como promotora para una de las inmobiliarias que desarrolla programas en Punchauca, cuyo nombre preferimos mantener en secreto para proteger su identidad.

- ¿Y cómo compran los terrenos a los parceleros?

-Los dueños de la empresa conversan con los parceleros y ellos deciden vender o no.

- ¿Y la compra a los parceleros es al contado?

-No, no pueden comprar al contado. Se va pagando de acuerdo a como se va realizando la venta de lotes.

\subsection{Intermediarios inmobiliarios}

Los promotores son sujetos que cumplen el rol de mediadores entre el usuario y la empresa inmobiliaria que oferta terrenos mediante programas. Un recorrido por esta parte del distrito de Carabayllo lleva a percibir una cantidad innumerable de paneles, afiches, avisos, gigantografías, casetas, que dicen: «Se vende lotes». Las casetas funcionan como un espacio de atención e interconexión entre el usuario el promotor de venta del lote. El mayor número de estos son mujeres, por el mismo hecho de que es tomado como un trabajo cercano al lugar donde viven, ya que varios de ellos tienen su casa en mismo Punchauca, incluso han comprado terrenos a las mismas inmobiliarias para quienes trabajan. Las empresas inmobiliarias hacen un descuento del sueldo mensual que reciben.

Existen dos modalidades de remuneración: a) fijo y b) por comisión. La primera modalidad consiste en una remuneración mensual por su fuerza de trabajo; mientras que la remuneración de los segundos depende de la cantidad de terrenos que vendan. La remuneración por comisión constituye un sistema de explotación. Varios de ellos son inmigrantes de primera generación de otras regiones del país que han vivido en otros distritos de Lima Metropolitana. La estrategia de las inmobiliarias en la concentración de capital se concreta, ya que muchos de los intermediarios o vendedores se convierten, al mismo tiempo, en usuarios. Establecen un contrato en que el precio de los terrenos se retiene del sueldo mensual de los promotores. Este contrato es visto como una oportunidad por los promotores para acceder a un lote, ya que muchos de ellos vivieron en casas alquiladas o en viviendas de familiares

La función que cumplen las promotoras evidencia grados de diferenciación socioeconómica. Cumplen el rol de intermediarios y hacen que los propietarios no sean conocidos de manera directa por los usuarios, hasta que por lo menos decidan definitivamente comprar el terreno.

\section{Reflexiones finales: El laberinto del mercado de suelo urbano}

La ausencia de un proyecto de ciudad, la inexistencia de una Ley de suelo urbano, la infracción y la instrumentación de herramientas regulatorias existentes y la apropiación de la lógica mercantil de las políticas económicas neoliberales, son algunos de los factores que conllevan la especulación inmobiliaria, el acelerado proceso de urbanización y el tráfico de terrenos tanto en áreas de comunidades campesinas aledañas como en territorios agrícolas periurbanos como Punchauca. Los precios del lote pueden subir dependiendo de cada inmobiliaria. Actualmente los precios oscilan entre 350 y 400 dólares el metro cuadrado.

El Perú, en la actualidad, no cuenta con un plan de desarrollo urbano, existen planes puntuales pero no uno que rija el desarrollo de la ciudad. La herramienta de formalización de una propiedad, desde el 2006, es la constancia municipal. El cambio de uso es también firmado por el gobierno municipal, lo que puede llevar a una relación clientelar y patronazgo. Nuestros informantes señalan que el gobierno municipal permite la lotización de los terrenos agrícolas a las inmobiliarias sin los estudios técnicos necesarios para el cambio de uso, visan el plano sin un estudio pertinente y se permite la lotización de áreas agrícolas periurbanas sin 
cambiar el uso del suelo, lo que hace que las empresas inmobiliarias puedan tener acceso a la compra de tierras agrícolas sin mayores dificultades y a la venta de lotes de manera especulativa. La compra y venta se realiza en una Notaría sin mayores restricciones, solo depende que las partes, representante de la empresa inmobiliaria y el parcelero, estén de acuerdo. Por ello, es importante, incluso, estudiar el sentido de estas herramientas, como la Constancia de Posesión, así como de las instituciones implicadas en los procesos de posesión de los espacios.

Se han presentado algunos conflictos y tensiones entre los parceleros y los dirigentes de la cooperativa, fundamentalmente debido a que la elite dirigencial nunca presenta balances sobre los manejos de las cuatro hectáreas que dejaron para la cooperativa. Manifiestan que incluso los dirigentes trafican terrenos vacíos, es decir, localizan las áreas no ocupadas para luego venderlas. Son estas razones las que han permitido la pérdida de confianza por los parceleros en la estructura dirigencial.

Por otro lado, respecto a los sujetos involucrados en el mercado de suelo urbano, Coincidimos con Morales ${ }^{6}$ cuando señala que no debemos imaginar encontrar comportamientos puros de los tipos de propietarios descritos, por el contrario, existen combinaciones de comportamientos así como procesos de conversión de un tipo de propietario a otro. Existen evidencias de que en estos últimos años, por ejemplo, los propietarios usuarios en Punchauca han devenido en propietarios inversionistas, en el sentido que buscan consolidarse como desarrolladores de programas inmobiliarios tanto en mismo Punchauca como en otras partes del valle del Chillón.

Los deseos de algunos propietarios patrimonialistas, de manera especial de aquellos con resistencia al desarrollo del mercado de suelo urbano por asuntos éticos y políticos, son limitados por el tiempo. Los cambios espaciales por el mercado de suelo sugieren aspectos irreversibles como la reproducción de áreas de producción agrícola, por lo menos no en el mediano plazo.

Otro aspecto que marca el comportamiento de los sujetos de mercado de suelo urbano y la apropiación del espacio es la alegalidad, los sujetos no solo se mueven en dimensiones de la legalidad o la ilegalidad, sino en ámbitos grises que implica el uso instrumental

6 Véase Morales S. (2005b). de diversas herramientas tanto legales como ilegales, las empresas inmobiliarias por más formales que se muestren, pueden estar inmersos en prácticas ilícitas y delictivas. Tal vez la alegalidad, y no la informalidad ${ }^{7}$, marque la forma de relación social de la sociedad peruana de hoy, sobre todo en la posesión del espacio, los bienes y servicios y su relación con las instituciones del Estado.

Finalmente, en Punchauca, encontramos dos principales características del mercado de suelo urbano:

La primera es que constituye empresas inmobiliarias principalmente promotoras y no empresas constructoras, lo que sí sucede en otras zonas de Carabayllo. Las diferentes empresas inmobiliarias existentes están orientadas solo a la venta de terrenos y no a la construcción de viviendas, lo que sí se encuentran en San Pedro de Carabayllo, centro poblado que se encuentra a la margen derecha del río Chillón. La presencia de este tipo de empresas promotoras permite la continuidad de la expansión de la ciudad de manera horizontal y una acelerada reducción de áreas agrícolas. La construcción de las viviendas, en tanto se da manera posterior a la compra, depende siempre de la capacidad de ingreso económico de los mismos usuarios que buscan comprar un lote. Es decir, el desarrollo inmobiliario en Punchauca, bajo estas características, reproduce la diferenciación socioeconómica en varios aspectos: en la adquisición del terreno, que varía en el tiempo y la ubicación del terrenos, los terrenos ubicados cercanos a las vías (avenidas o calles) tienen mayor costo y aumentan de manera exponencial en poco tiempo, por lo que es cada vez más difícil que las familias de condiciones económicas bajas puedan acceder a un terreno en estos espacios. Segundo, en el tipo de vivienda que se construye luego de la compra.

Una segunda característica es comporta empresas inmobiliarias externas (inversionistas), empresas autónomas formadas principalmente por hijos de parceleros, así como a propietarios que mantienen resistencia ante los procesos de urbanización debido a diversas motivaciones. Los sujetos beneficiarios de la Reforma Agraria bien establecen alianzas con inmobiliarias externas o dejan que sus hijos manejen la empresa. Todas estas inmobiliarias brindan a los usuarios servicios básicos (agua y luz) provisionales y son

7 Martuccelli (2015) plantea que la informalidad, a diferencia de la ilegalidad, se habría convertido en el imaginario del lazo social de la ciudad desde hace algunas décadas. 
de carácter especulativo. Las empresas administradas por los hijos de los parceleros, generalmente, van a la zaga de los inversionistas en cuanto a precios de los terrenos. Y muestran «flexibilidad en los pagos» y los servicios que ofrecen las diferentes inmobiliarias son provisionales.

Un aspecto que queda por investigar en estos espacios en tensión son las formas como se establecen y mantienen las estructuras de afinidad (amistad y de parentesco) en contextos de sociedad de mercado. Al parecer, estas estructuras de afinidad tienen gran importancia en la permanencia de las relaciones clientelares y la práctica de la alegalidad.

\section{Referencias bibliográficas}

Arroyo Hurtado, Roberto (Coordinador) (2015). Lima Norte. Caracterización económica y proyecciones sociales. Lima: Fondo Editorial de la Universidad de Ciencias y Humanidades.

Arroyo Hurtado, Roberto (2014). «Prólogo». En: Pedro Jacinto Pazos. Micronegocios vs. Megamercados. Otros sentidos de identidad, distinción y consumo en los microempresarios de Lima Norte. Lima: Fondo Editorial Universidad Nacional Mayor de San Marcos.

Arroyo Hurtado, Roberto y Romero Reyes, Antonio (2005). «Lima Metropolitana: del monocentrismo a la policentralidad». VII Seminario Nacional de la Red de Centros Académicos para el Estudio de Gobiernos Locales, Buenos Aires, 15 y 16 de setiembre.

Ávila SÁNChez, Héctor (2009). «Periurbanización y espacios rurales en la periferia de las ciudades. En: Estudios Agrarios. México: Procuraduría Agraria.

Ávila SÁnchez, Héctor (2001). «Ideas y planteamientos teóricos sobre los territorios periurbanos. Las relaciones campo-ciudad en algunos países de Europa y América». En: Investigaciones Geográficas. Boletín del Instituto de Geografía, N 45. México: UNAM.

Calderón, Julio (2006). Mercado de tierras urbanas, propiedad y pobreza. Lima: SINCO Editores.

CALDERón, Julio (2005). La ciudad ilegal. Lima en el siglo XX. Lima: UNMS.

CALderón, Julio (1998). «Mercado de tierras en áreas agrícolas periurbanas de Lima». Debate Agrario, No 28, pp.122, Lima.

De Soto, Hernando (1986). El otro sendero. Lima: Instituto Libertad y Democracia.
Entrena Durán, Francisco (2005). «Procesos de periubanización y cambios en los modelos de ciudad. Un estudio europeo de casos sobre sus causas y consecuencias». En, papers. Pp. 59-88.

Instituto Nacional de Estadística e Informática y UNFPA (2010). Mapa de pobreza provincial y distrital 2009. El enfoque de la pobreza monetaria. Lima: INEI/UNFPA

Jacinto Pazos, Pedro (2014). Micronegocios vs megamercados: Otros sentidos de identidad, distinción y consumo en los microempresarios de Lima Norte. Lima: Fondo Editorial UNMSM.

Lefebvre, Henri (2013 [1974]). La producción del espacio. Madrid: Capitán Swing.

Lefebvre, Henri (1978). De lo rural a lo urbano. Barcelona: Ediciones Península.

Lefebvre, Henri (1974). La vida cotidiana en el mundo moderno. Madrid: Alianza Editorial.

Malpica, Carlos (1975). Los dueños del Perú. Lima: Ediciones Peisa. Octava edición.

Martuccelli, Danilo (2015) Lima y sus arenas. Poderes sociales y jerarquias culturales. Lima: Cauces Editores

Matos Mar, José (1986). Desborde popular y crisis del estado: el nuevo rostro el Perú en la década del 80. Lima: IEP.

Monge, Carlos (2012). «Lo rural y lo urbano en el Perú de hoy». En: Teresa Cabrera (Coord.). Perú Hoy: Lo urbano en el Perú. Lima: Desco, pp.19-32.

Morales Schechinger, Carlos (2005a). «Conceptos avanzados de suelo urbano». Texto preparado para el curso de Educación a distancia sobre Planeación Urbana y Gestión del Suelo en ciudades Mexicanas. Abril, 2005.

Morales Schechinger, Carlos (2005b). «Curar o vacunar, dos políticas en tensión: la regularización vs las reservas territoriales en el desarrollo urbano sustentable».

Pimentel SÁnchez, Nekson (2017a). «Subalternos autónomos: Transformaciones periurbanas y tráfico de tierras en el contexto de una sociedad de mercado: Carabayllo, Lima». Tesis para Optar el Título Profesional de Licenciado». Lima: UNMSM/Facultad de Ciencias Sociales.

Pimentel Sánchez, Nekson (2017b) «Entrevista a Gustavo Riofrío: 'Se mueven millones en el tráfico de terrenos'” En: Sucesos, semanario de actualidad, Año 1, $\mathrm{N}^{\circ} 11$. Lunes, 15 de mayo, pp. 16-17.

Pimentel SÁnchez, Nekson (2017c). «Parceleros y su resistencia por la tierra ante la urbanización: Punchauca, Carabayllo, Lima». Caso 140. La Paz: IIPDRS. En Línea: http://porlatierra.org

Pimentel Sánchez, Nekson (2014). «El laberinto de la periurbanización y la cultura política en Carabayllo.» En: 
Estructura Salvaje, Año 3, № 3. Lima: Lluvia Editores, pp. 55-72.

Quispe Pastrana, Edgar y Santiago Tácunan Bonifacio (2011). Carabayllo: Génesis de Lima Norte. Lima: Municipalidad de Carabayllo.

Remy, María Isabel (2009). "Las urbes, las ciudades y la población rural». En: Revista Argumentos, Ano 3, №2. Lima: IEP.

Távara Castillo, José (2007). Historias entrelazadas. Lima: Esperanza Tiers Monde.
Távara Castillo, José (2014). Carabayllo: Nuestro distrito. Lima: Katz.

Thays V., Luis Iván (1996). Evolución del mercado de tierras y tenencias. Lima: USAID/Gobierno Peruano.

Vega Centeno, Pablo (2004). «De la barriada a la metropolización: Lima y la teoría urbana en la escena contemporánea». En Las ciudades en el Perú. Lima: Desco.

Williams, Raymond (2001). El campo y la ciudad. Buenos Aires: Paidós. 